\title{
Первый опыт применения флюоресцентной лимфографии при раке
}

\section{желудка}

\begin{abstract}
Цель работы: оценка результатов первого опыта применения флюоресцентной лимфографии в ходе лимфодиссекции D2 при раке желудка.

Материалы и методы. Флюоресцентная лимфография выполнена двум пациентам. Первому пациенту с раком верхней трети желудка без проростания кардии с регионарной лимфаденопатией была выполнена гастрэктомия с лимфодиссекцией D2. Послеоперационных осложнений не было. Начиная с 5-х суток проводилось зондовое питание. На 10 сутки зонд извлечён и начато энтеральное питание. Больной выписан на 12 сутки. Второму пациенту с инфильтративной опухолью антрального отдела со стенозом привратника и регионарной лимфаденопатией выполнена субтотальная резекция с лимфодиссекцией D2. В послеоперационном периоде развился наружный панкреатический свищ, закрывшийся через 14 суток. Зонд извлечен на 10 сутки. Больной выписался на 15 сутки. В обоих случаях в начале операции перитуморозно введено по 10 мл растворённого индоцианина зелёного. Использовалась специальная видеосистема фирмы KarlStorz с oптикой-экзоскопом Vitom II.

Результаты исследований и их обсуждение. Через 50-60 минут в обоих случаях при осмотре в свете, близком к инфракрасному, была зафиксирована не только флюоресценция первичной опухоли, но и достаточно яркое свечение регионарных лимфоузлов, причём более активная флюоресценция наблюдалась в лимфоузлах, относящихся к основному пути лимфоотока. Также флюоресценция позволила визуализировать лимфоузлы в толще жировой ткани, которые на первый взгляд не определялись, и позволила проконтролировать их полное отсутствие по завершению систематической лимфодиссекции. После завершения лимфодиссекции флюорисцирующих лимфоузлов не наблюдалось. Таким образом, флюоресцентная лимфография позволила проконтролировать полноту выполненной лимфодиссекции.
\end{abstract}

Ключевые слова: индоцианин зелёный; флюоресцентная лимфография; лимфодиссекция D2; рак желудка.

Постановка проблемы и анализ последних исследований и публикаций. В настоящее время общепризнанным стандартом операций при раке желудка является гастрэктомия и субтотальная резекция с лимфодиссекцией D2. Несмотря на хорошо отработанную технику лимфодиссекции с удалением 12 групп лимфоузлов 1-го и 2-го порядка, необходим объективный контроль её полноты. В настоящее время появилась возможность такого контроля с помощью флюоресценции с использованием индоцианина зелёного как при лапароскопических, так и при открытых операциях.

Цель работы: оценка результата первого опыта применения флюоресцентной лимфографии в ходе лимфодиссекции D2 при операциях при раке желудка.

Материалы и методы. Новую технологию мы применили у двух пациентов с использованием следующего оборудования фирмы KarlStorz: источник света D-Light P, оптика-экзоскоп Vitom II, специальный световод, видеосистема Image 1S. У первого пациента в возрасте 52 года с индексом массы тела $22 \mathrm{kг} / \mathrm{M}^{2}$ имела место экзофитная опухоль верхней трети желудка, поражающая переднюю стенку, без прорастания кардии, диаметром до 7 см, с регионарной лимфаденопатией и солитарным метастазом диаметром 3 см в IV сег- менте печени, по данным компьютерной томографии. По данным эндоскопии - экзофитная опухоль с изъязвлением той же локализации, гистологически - низкодифференцированная эпителиальная опухоль. У второго пациента в воз-

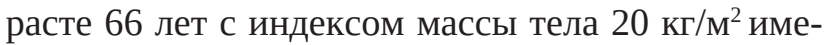
ла место инфильтративная опухоль антрального отдела со стенозом привратника, вплотную прилежащая к головке поджелудочной железы, диаметром до 4 см с регионарной лимфаденопатией, по данным компьютерной томографии. Ендоскопически - та же картина, гистологически - низкодифференцированная аденокарцинома. У первого пациента в ходе выполнения гастрэктомии обнаружена опухоль передней стенки верхней трети желудка, не доходящая до кардии на 3 см, с прорастанием в серозный слой, явлений канцероматоза не выявлено. У второго пациента по ходу субтотальной резекции выявлена опухоль антрального отдела, прорастающая в головку поджелудочной железы, ближе к перешейку, на протяжении 1,5 - 2 см с глубиной инвазии около 0,5 см; явлений канцероматоза и отдалённых метастазов не выявлено. В обоих случаях, после установки ретракторов (типа Черни, Бюхвальтеpa), на специальном L - образном фиксаторе установлен экзоскоп Vitom II. В начале операции пе- 
ретуморозно, в четырёх квадрантах, введено по 2,5 мл растворённого индоцианина зелёного (флакон 25 мг и 10 мл физиологического раствора). У первого пациента в процессе лимфодиссекции увеличеные в размерах и количестве лимфоузлы обнаружены преимущественно в области левой желудочной артерии и чревного ствола (группа 7 и 9 по классификации Японского общества по изучению рака желудка), по верхнему краю поджелудочной железы, в области ворот селезёнки и по большой кривизне в проксимальной её части (группа 4sb,10,11). У второго пациента в ходе лимфодиссекции конгломераты увеличенных лимфоузлов были обнаружены в области правой желудочносальниковой артерии и по ходу общей печёночной и левой желудочной артерии (группы 6,7,8).

Спустя 50-60 минут после перетуморозного введения индоцианина зелезного зафиксиро- вана не только флуоресценция первичной опухоли (рис. 1), но и достаточно яркое свечение регионарных лимфоузлов, причём более активная флюоресценция наблюдалась в лимфоузлах, относящихся к основному пути лимфооттока: в первом случае в области левой желудочной артерии (7 группа), во втором случае - в области правой желудочно-сальниковой артерии (6 группа) (рис. 2). Примечательно, что мелкие лимфоузлы, располагавшиеся в окружающей жировой клетчатке по ходу сосудов, были не видны при обычном свете, однако при осмотре в свете к близком к инфракрасному они легко обнаруживались (рис. 3, 4). Это позволило облегчить выполнение лимфодиссекции. После завершения лимфодиссекции и перевязки сосудов у основания (правая желудочно-сальниковая артерия, правая желудочная артерия, левая желудочная арте-

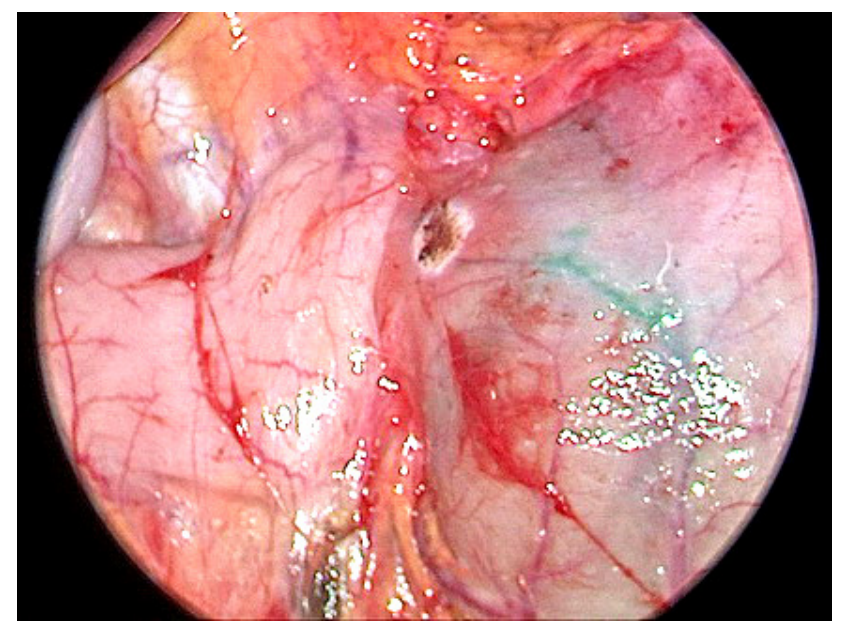

a

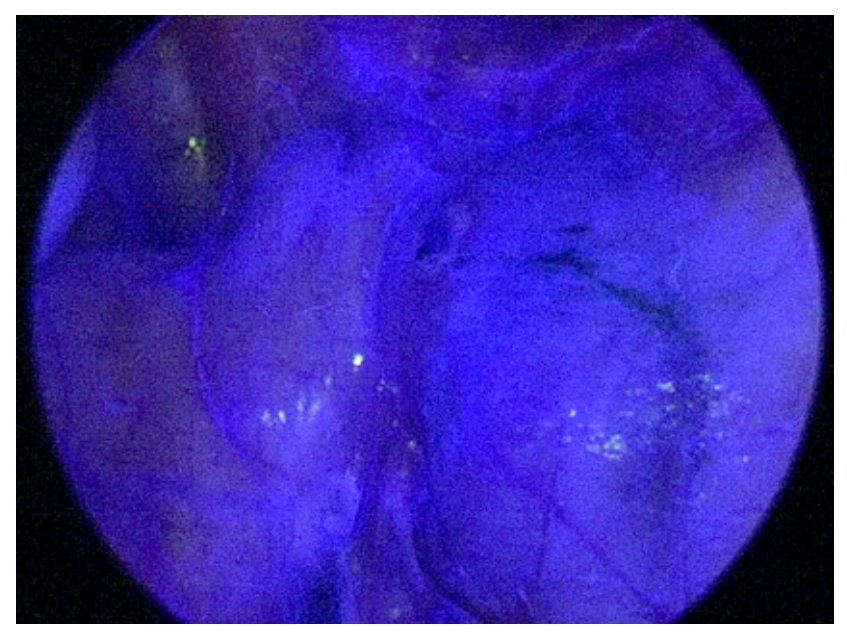

6

Рис. 1. Индоцианин зелёный введен перетуморозно: а - осмотр при обычном свете; б - осмотр в свете, близком к инфракрасному.

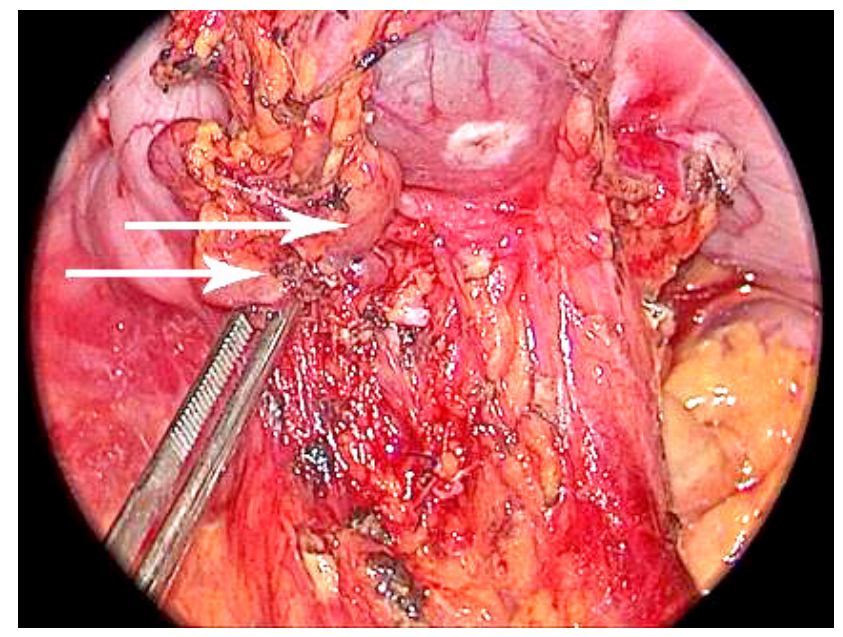

a

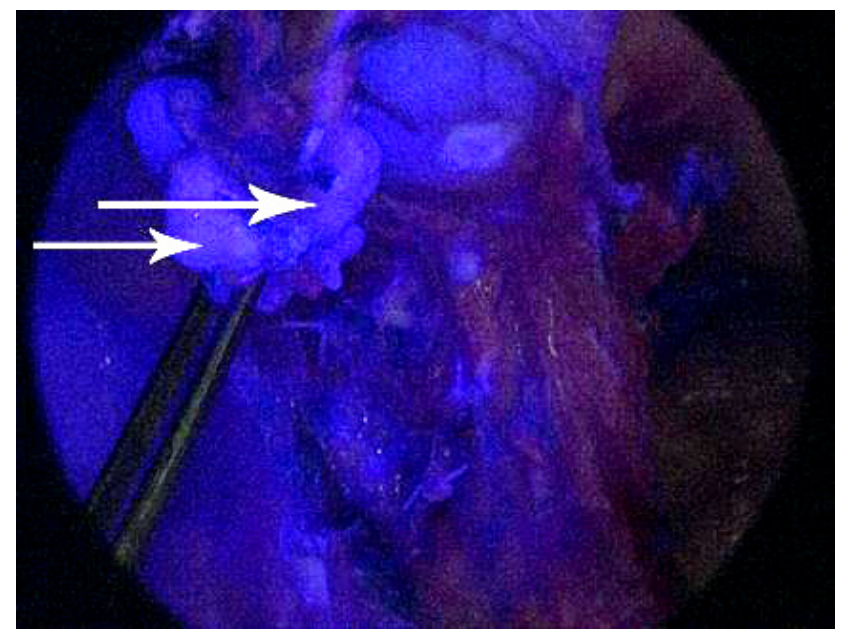

6

Рис. 2. Визуализация лимфоузлов 6 группы: а - осмотр при обычном свете; б - осмотр в свете, близком к инфракрасному, стрелка - лимфоузлы. 


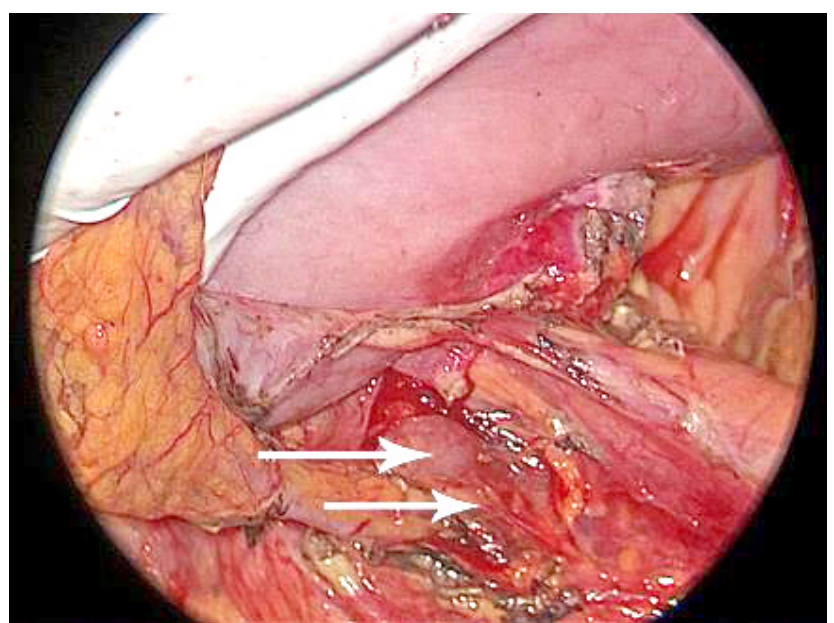

a

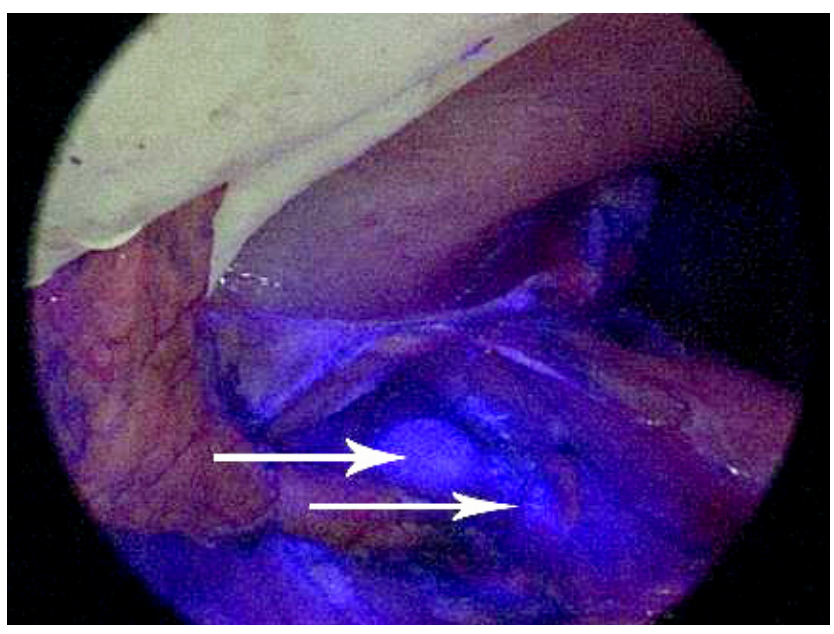

б

Рис. 3. Визуализация мелких, глубоко расположенных лимфоузлов 6 группы: а - осмотр при обычном свете; б - осмотр в свете, близком к инфракрасному, стрелка -лимфоузлы.

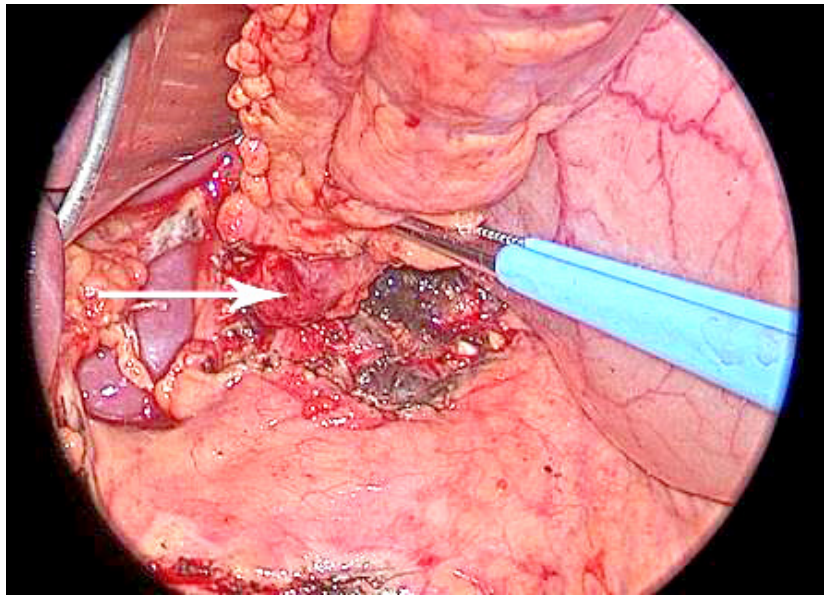

a

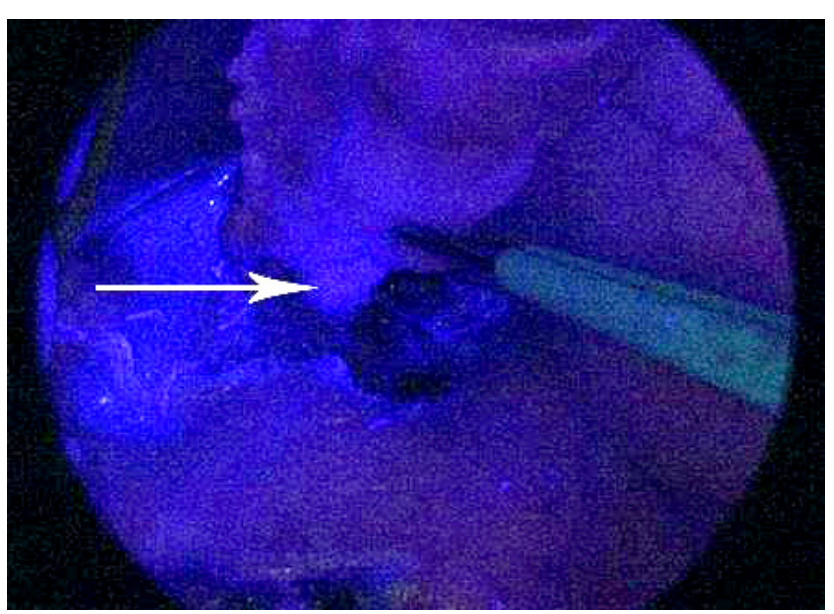

6

Рис. 4. Визуализация лимфоузлов 7 группы: а - осмотр при обычном свете; б - осмотр в свете, близком к инфракрасному, стрелка - лимфоузлы.

рия и короткие желудочные артерии в первом случае, левая желудочная артерия во втором случае) выполнен контрольный осмотр в свете, близком к инфракрасному: флюоресцирующих лимфоузлов обнаружено не было, что доказало полноту выполненной лимфодиссекции (рис. 5-7). В первом случае также была выполнена тщательная диссекция ворот селезёнки. Реконструктивный этап состоял в формировании позадиободочного эзофагоеюноанастомоза на отключенной по Ру петле с помощью циркулярного сшивающего аппарата диаметром 25 мм, конец-в-бок с укреплением анастомоза П-образными швами по всему периметру. Энтероэнтероанастомоз конец-в-бок был сформирован с отверстием в отводящей петле, которое использовалось для введения степлера и располагалось на расстоянии 40 см дистальнее эзофагоеюноанастомоза. Так же выполнена ати- пичная резекция IV сегмента печени. Во втором случае дополнительно выполнена краевая резекция поджелудочной железы в пределах здоровой ткани. Реконструктивный этап состоял в наложении впередиободочного гастроэнтероанастомоза з Брауновским соустьем. В обоих случаях за дистальные анастомозы проведены зонды для питания.

В первом случае послеоперационных осложнений не было. Начиная с 5-х суток проводилось зондовое питание. На 10 сутки зонд извлечён и начато энтеральное питание. Больной выписан на 12 сутки. Во втором случае в послеоперационном периоде закономерно развился наружный панкреатический свищ с небольшим дебитом, закрывшийся через 14 суток. Зонд извлечен на 10 сутки после рентгенологического контроля эвакуации из культи желудка (имел место стеноз привратника). Больной выписался на 15 сутки. 


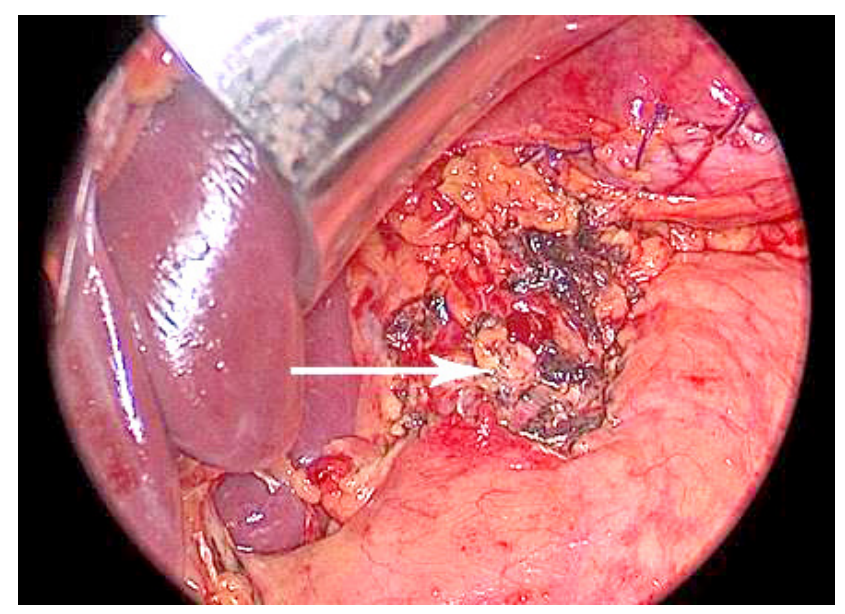

a

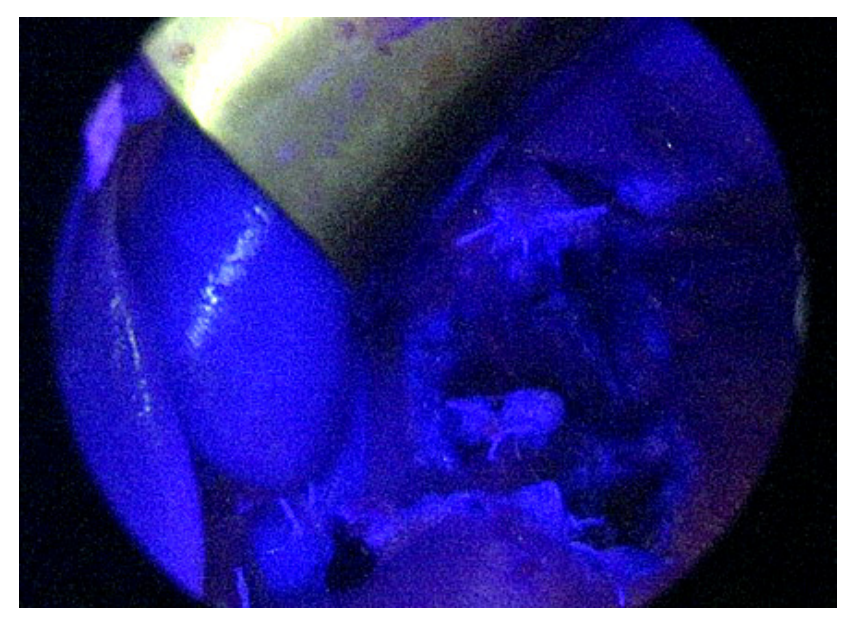

6

Рис. 5. Контроль полноты лимфодиссекции бассейна общей печеночной и левой желудочной артерии (7, 8 группа): а - осмотр при обычном свете; б - осмотр в свете, близком к инфракрасному, стрелка - культя левой желудочной артерии.

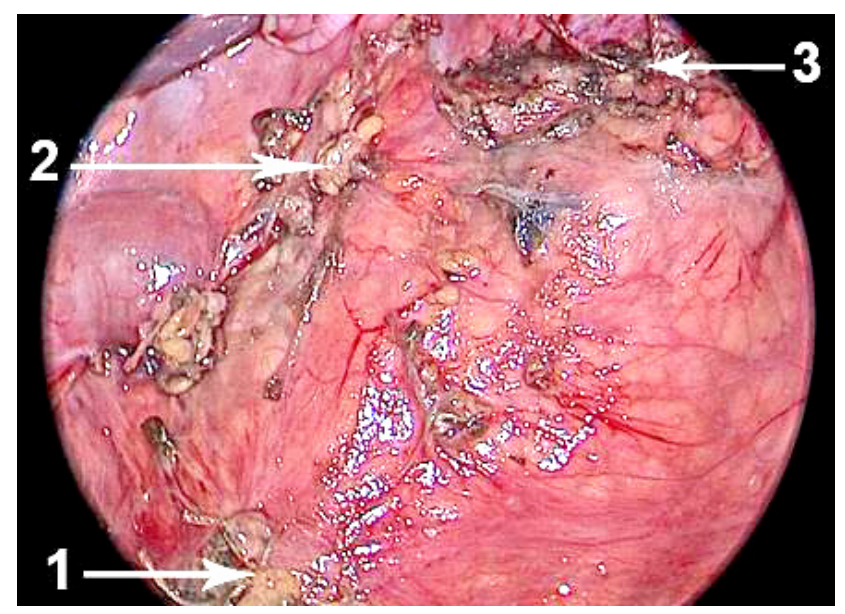

a

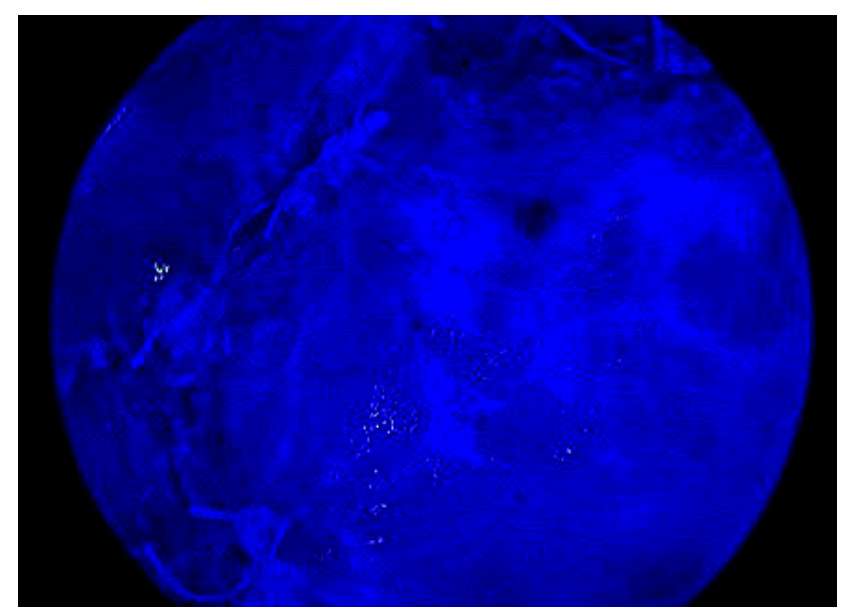

6

Рис. 6 Контроль полноты лимфодиссекции после гастрэктомии в области головки и тела поджелудочной железы: а - осмотр при обычном свете; б - осмотр в свете близком к инфракрасному, 1 - культя правой желудочно-сальниковой артерии, 2 - культя правой желудочной артерии, 3 - культя левой желудочной артерии.

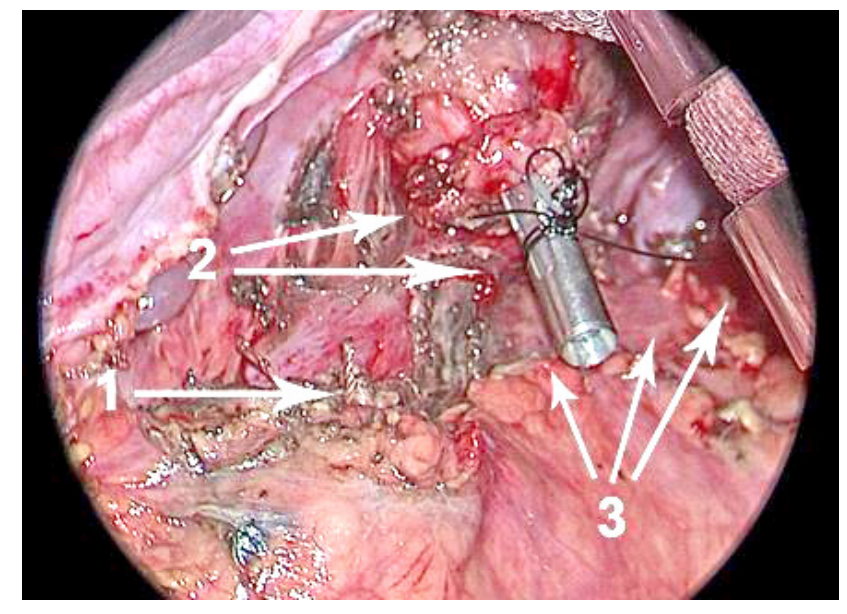

a

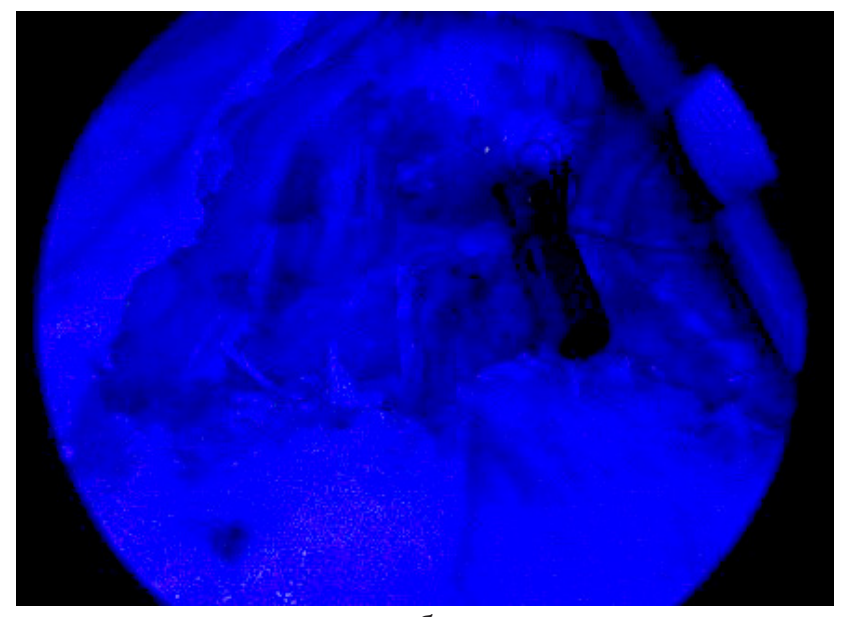

б

Рис. 7. Контроль полноты лимфодиссекции после гастрэктомии в области тела и хвоста поджелудочной железы: а - осмотр при обычном свете; б - осмотр в свете, близком к инфракрасному, 1 - культя левой желудочной артерии, 2 - зона паракардиальных лимфоузлов (1-2 группа), 3 - область ворот селезёнки (10-11 группа). 
Результаты гистологического исследования препаратов: в первом случае - низкодифференцированная аденокарцинома, прорастающая во все слои стенки, метастатическое поражение 8 из 15 удаленных лимфоузлов; во втором случае - низкодифференцированная аденокарцинома с перстневидными клетками, выходящая за пределы стенки желудка с поражением 10 из 17 удаленных лимфоузлов.

Результаты исследований и их обсуждение. Технология флюоресцентной навигации при лимфодиссекции или флюоресцентной лимфографии является очень перспективным направлением при различных онкохирургических вмешательствах, в частности при гастрэктомии и субтотальной резекции желудка, право- и левосторонней гемиколэктомии. Особенно эти преимущества выражены при лапароскопических операциях, которые все чаще и чаще выполняются в мире при указанных локализациях. Первым основным преимуществом флюоресцентной лимфографии является визуализация лимфоузлов, что, несомненно, улучшает качество лимфодиссекции, как показал ряд работ [1, 2].

Вторым, изучаемым в настоящее время, преимуществом является возможность селективного удаления сторожевых лимфоузлов, накопивших краситель, что пропагандируют некоторые авторы [2, 4, 5]. Пока проведенные исследования не доказали возможность применения селективного подхода к лимфодиссекции при раке желудка согласно концепции сторожевого лимфоузла [3]. Поэтому требуются более масштабные исследования. В перспективе возможно появление ещё одного преимущества: технология моноклональных

\section{СПИСОК ЛІТЕРАТУРИ}

1. Fluorescent-guided surgery for sentinel lymph node detection in gastric cancer and carcinoembryonic antigen targeted fluorescent-guided surgery in colorectal and pancreatic cancer / F. A. Vuijk, D. E. Hilling, J. S. D. Mieog [et al.] // Surg. Oncol. - 2018 - Vol. 118 (2). - P. 315-323. DOI: 10.1002/jso.25139.

2. Laparoscopic sentinel node navigation surgery for early gastric cancer / S. Kinami, T. Kosaka // Transl. Gastroenterol. Hepatol. - 2017. - Vol. 2 (42). DOI: 10.21037/tgh.2017.05.02.

3. Novel surgical approach based on the sentinel node concept in patients with early gastric cancer / S. Natsugoe, T. Arigami,

\section{REFERENCES}

1. Vuijk, F.A., Hilling, D.E., Mieog, J.S.D., \& Vahrmeijer, A.L. (2018). Fluorescent-guided surgery for sentinel lymph node detection in gastric cancer and carcinoembryonic antigen targeted fluorescent-guided surgery in colorectal and pancreatic cancer. антител, связанных флюоресцирующим препаратом [1]. Это откроет перспективу к воплощению концепции сторожевого лимфоузла на качественно новом уровне.

В нашем исследовании мы продемонстрировали возможность флюоресцентной лимфографии для оценки полноты лимфодиссекции: флюоресценция позволила визуализировать лимфоузлы в толще жировой ткани, которые, на первый взгляд, не определялись, и позволила проконтролировать их полное отсутствие по завершению систематической лимфодиссекции. Интересным и закономерным фактом было то, что флюоресценция была более активной в лимфоузлах, являвшихся основным коллектором лимфооттока при определенной локализации опухоли.

Естественно, требуется дальнейший набор материала как при открытых, так и при лапароскопических операциях, для более конкретных выводов. Пока основным выводом, соответствующим данным литературы, является то, что флюоресцентная лимфография облегчает выполнение систематической лимфодиссекции D2.

Выводы. 1. Флюоресцентная лимфография с помощью специальной видеосистемы KarlStorz и индоцианина зелёного легко выполнима при открытой гастрэктомии и субтотальной резекции желудка.

2. Флюоресцентная лимфография облегчает выполнение систематической лимфодиссекции D2.

3. Необходим дальнейший набор материала для доказательства влияния этого подхода на онкологические результаты и выявления других закономерностей применения флюоресцентной лимфографии.
Y. Uenosono [et al.] // Ann. Gastroenterol. Surg. -2017. - Vol. 1 (3). - P. 180-185. DOI: 10.1002/ags3.12027.

4. Symeonidis D. Techniques and current role of sentinel lymph node (SLN) concept in gastric cancer surgery / D. Symeonidis, K. Tepetes // Front Surg. - 2019 - Vol. 5 (77). DOI: 10.3389/ fsurg.2018. 00077.

5. Update on the indications and results of sentinel node mapping in upper GI cancer / M. Takeuchi, H. Takeuchi, H. Kawakubo [et al.] // Clin. Exp. Metastasis. - 2018. - Vol. 35 (5-6). - P. 455461. DOI: 10.1007/s10585-018-9934-6. 
3. Natsugoe, S., Arigami, T., Uenosono, Y. \& Yanagita, S. (2017). Novel surgical approach based on the sentinel node concept in patients with early gastric cancer. Ann. Gastroenterol. Surg., 1 (3), 180-185.

4. Symeonidis, D., \& Tepetes, K. (2019). Techniques and current role of sentinel lymph node (SLN) concept in gastric cancer surgery. Front Surg., 5 (77).

5. Takeuchi, M., Takeuchi, H., Kawakubo, H. \& Kitagawa, Y. (2018). Update on the indications and resuelts of sentinel node mapping in upper GI cancer. Clin. Exp. Metastasis, 35 (5-6), 455-461.

Получено 17.12.2018

Электронный адресс для переписки: endosurgery2017@gmail.com

A. V. MALINOVSKY, M. M. GALIMON, S. Y. BADION

Odesa National Medical University

\title{
FIRST EXPERIENCE OF FLUORESCENCE-GUIDED LYMPH NODE DISSECTION FOR GASTRIC CANCER
}

\begin{abstract}
The aim of the work: evaluation of results of the first experience in use of fluorescence-guided D2 lymph node dissection lymph for gastric cancer.

Materials and Methods. Fluorescence lymphography was performed in two patients. The first patient with cancer of upper third of stomach without involvement of cardia, with regional lymphadenopathy, underwent gastrectomy with D2 lymph node dissection. There was no postoperative complications. Tube feeding started from the 5th day. Intestinal tube was extracted and enteral feeding started on the 10th day. The patient was discharged on the 12th day. A second patient with an infiltrative tumor of antral part and stenosis of pylorus, with regional lymphadenopathy, underwent subtotal gastrectomy with D2 lymph node dissection. External pancreatic fistula evolved postoperatively and closed on the 14 day. The intestinal tube was removed on the 10th day. The patient was discharged on the 15th day. In both cases, at the beginning of procedure, $10 \mathrm{ml}$ of indocyanine green were injected around the tumor. A special system by KarlStorz with exoscope optics Vitom II was used.

Results and Discussion. In both cases, after 50-60 minutes post injection, examination in near-infrared light showed fluorescence of the primary tumor and bright fluorescence of the regional lymph nodes, with more active fluorescence observed in the lymph nodes belonging to the main lymph flow basin. Also, the fluorescence allowed visualizing the lymph nodes in the thickness of adipose tissue, which could not be determined, and allowed to control their absence on completion of systematic lymph node dissection. After completion of dissection, no fluorescence of lymph nodes was observed. Thus, fluorescence allowed to check the completeness of lymph node dissection.
\end{abstract}

Key words: indocyanine green; fluorescence lymphography; D2 lymph node dissection; gastric cancer.

\section{А. В. МАЛИНОВСЬКИЙ, М. М. ГАЛІМОН, С. Ю. БАДІОН}

Одеський національний медичний університет

\section{ПЕРШИЙ ДОСВІД ВИКОРИСТАННЯ Ф.ЛЮОРЕСЦЕНТНОӤ ЛІМФОГРАФІЇ ПРИ РАКУ ШІЛУНКА}

\begin{abstract}
Мета роботи: оцінка результатів першого досвіду застосування флюоресцентної лімфографії в ході лімфодисекції D2 при раку шлунка.

Матеріали і методи. Флюоресцентна лімфографія виконана двомпацієнтам. Першому пацієнту з раком верхньої третини шлунка без проростання кардії з регіонарною лімфаденопатією була виконана гастректомія з лімфодисекцією D2. Післяопераційних ускладнень не було. Починаючи з 5-ї доби проводилося зондове харчування. На 10 добу зонд витягнули і розпочали ентеральне харчування. Хворого виписанли на 12 добу. Другому пацієнту з інфільтративною пухлиною антрального відділу зі стенозом воротаря і регіонарною лімфаденопатією виконано резекцію з лімфодисекцією D2. В післяопераційному періоді розвинулася зовнішня панкреатична нориця, яка закрилася через 14 діб. Зонд витягнули на 10 добу. Хворого виписали на 15 добу. В обох випадках на початку операції перитуморозно введено по 2,5 мл розчиненого індоціаніну зеленого. Використовували спеціальну відеосистему фірми KarlStorz з оптикою-екзоскопом Vitom II.

Результати досліджень та їх обговорення. Через 50-60 хвилин в обох хворих при огляді в світлі близькому до інфрачервоного зафіксовано не тільки флюоресценцію первинної пухлини, але і досить яскраве світіння регіонарних лімфовузлів, при чому більш активна флюоресценція спостерігалася в лімфовузлах, які належать до основного шляху лімфовідтоку. Також флюоресценція дозволила візуалізувати лімфовузли в товщі жирової тканини, які, на перший погляд, не визначалися, i проконтролювати їх повну відсутність після систематичної лімфодисекції. Після завершення лімфодисекції флюоресціюючих лімфовузлів не спостерігали. Таким чином, флюоресцентна лімфографія дозволила проконтролювати повноту виконаної лімфодисекції.
\end{abstract}

Ключові слова: індоціанін зелений; флюоресцентна лімфографія; лімфодисекція D2; рак шлунка. 